\title{
Enhancing the Effectiveness of School Advertisement in Taiwan: Customer-Focused Message Persuasiveness, Exposure Frequency, and Peak Timing
}

\author{
Hsuan-Fu $\mathrm{Ho}^{1}$ \\ ${ }^{1}$ National Chiayi University, Taiwan \\ Correspondence: Hsuan-Fu Ho, National Chiayi University, Taiwan. E-mail: hfho2264780@ gmail.com
}

Received: November 29, 2014

Accepted: December 26, 2014

Online Published: January 25, 2015

doi:10.5539/ibr.v8n2p100

URL: http://dx.doi.org/10.5539/ibr.v8n2p100

\begin{abstract}
Marketing has become an essential function for schools in Taiwan given the steadily increasing competition in the educational market, and advertising media have been the most widely used promotion weapon adopted by educational institutions. However, since marketing has long been an unknown territory to educational institutions, many schools have bemoaned that they face tremendous difficulties in developing their marketing mix. This research aims to explore how students at different levels use what media to search for which information at what time. 1200 questionnaires were administered to students at different educational levels across Taiwan. Finally, we demonstrated how the research findings can be used to improve institutions' marketing efforts.
\end{abstract}

Keywords: school marketing, school selection, advertisement, media mix

\section{Introduction}

Marketing has become an essential function for schools in Taiwan given the steadily increasing competition in the educational market, and birthrate decline surely contributes a great deal to this matter. In the past two decades, Taiwan has experienced a dramatic fertility decrease, and the situation has become so critical that, in 2009 , with the fertility rate falling to 0.829 , Taiwan's birthrate ranked lowest in the world. Unfortunately, this is not the end of the trend, and the student population is projected to further shrink in the future. This dramatic birthrate decline not only predicts a manpower shortage in the future, but also means a tremendous shortage of students for schools at every level.

In Taiwan, schools at every level have been severely affected by this dramatic demographic change. To deal with the fertility issue, as well as enhance the efficiency of the educational resource attribution, Taiwan's government has mandated a school closure policy at the primary and secondary levels, declaring that schools that fail to recruit enough students to satisfy the pre-determined class size set by the government will be closed or merged into other schools. In light of this policy, schools at the primary and secondary levels are desperately adopting a variety of marketing campaigns to survive the ferocious competitive educational market.

Schools at the higher educational level are no exception; they are also intensely influenced by the population decline. However, given that the aforementioned fertility decline was one of the major reasons for student shortages, the audacious "Broadly Expanding the Higher Educational Institutions" policy proposed by the government in 2000 caused even more harm to schools at the higher educational level. In order to provide all students willing to receive a higher education with a place in the universities, Taiwan's government proposed a devastating policy to vastly expand its higher educational system; thanks to this imprudent policy, the number of higher educational institutions has rapidly increased, growing from 46 in 1990 to 148 in 2010. As the accommodation vacancies enormously exceed the number of students, most universities were forced to close or compromise their educational quality to maintain a financial balance. Certainly, again, marketing weapons were desperately adopted.

Advertising media have been the most important promotion weapon adopted by educational institutions to attract student applicants. However, different media contribute differentially in customer exposure and persuasion, and they may complement each other in a marketing-communication campaign (Dijkstra, Buijtels, \& Van Raaij, 2003). Therefore, the traditional way of picking individual media for promotion has been discarded by most educational institutions, and the contemporary approach is to arrange a combination and permutation of media, 
generally called "media mix", to ensure that the effect of the advertisements are maximized (Chang, Wu, Tseng, $\mathrm{Su}, \& \mathrm{Ko}, 2012)$.

To optimize the media mix, a thorough understanding of the weaknesses and strengths of different media is essential. Unfortunately, as marketing has long been an unknown territory to educational institutions in Taiwan, many schools have lamented that they face tremendous difficulties in developing their marketing mix and that their advertisement campaigns are often far from cost effective. Hence, a guide to assist schools in media mix development is imperative.

There is certainly a vast amount of literature discussing the various forms of media in the business field, but little has been conducted to understand how the advertising media might be used in the educational context, which is quite different from the traditional business context (Rizvi \& Khan, 2010). Given that more educational institutions are adopting advertisements through a variety of outlets, it is important to conduct thorough research on how schools can effectively use media advertisements. This research is thus aimed to examine the strengths and weaknesses of different media in the education context, with a specific focus on media used by students in their school-selection behaviors.

\section{Literature Review}

\subsection{Consumer-Focused Advertisement}

A consumer behavior is a collection of tasks, processes, or procedures that a consumer goes through to accomplish the purchasing or consuming behavior (Subramaniam, Shaw, \& Gardner, 2000). Generally, studies focusing on consumer behaviors involve issues such as product perception, information collecting methods, attitudes toward and beliefs about certain products, purchase and consumption decision-making processes, and behavioral changes at different stages.

As advertisements aim to influence the purchasing procedures of consumers, it is important to explore their information-searching behaviors before developing advertising plans (Slade, 2002). Traditionally, advertisements were believed to appeal mostly to the irrationals, and consumers were perceived as blind receivers who accepted advertising messages surreptitiously and passively. Under this assumption, consumer behavior patterns could be ignored when developing advertisements plans because consumers simply absorbed every message presented by advertisers, without much selection.

However, this traditional theory was discarded decades ago. Chaudhuri and Buck (1995) and Slade (2002), for example, argues that the process of the advertisement that influences consumers is rational at every stage of their consuming procedures; therefore, the practice of advertising should be based on assumptions that those they address are rational and that consumers will act rationally if convinced. Sometimes the messages conveyed in the advertisement are not objectively true because advertisers often intentionally misuse statistics or suggest false analogies, but this is not a problem because audiences generally watch television or read newspaper advertisements with a critical attitude, and they screen and accept messages that to them seem to be rational and then act on them rationally.

As consumers are very different individuals who tend to be influenced by mass media advertisements differently in terms of how they feel about the advertisements and how they judge the content of advertisements, it is crucial for marketers to establish advertising strategies in line with the consumers' purchase habits if the aim is to promote their final purchase (Kopperschmidt \& Stute, 2009; Esteban \& Hernández, 2012).

\subsection{Measures of Media Effectiveness}

Advertisement media are the channels or outlets for connecting consumers and industries, and effective media is often measured by its ability to convey messages that can successfully influence attitudes and purchase intentions among targeted customers. The influence of media on audiences can be summarized as informing, framing, persuading, and sometimes entertaining; therefore, they are widely used by business or political parties to convey messages (Collins, Abelson, Pyman, \& lavis, 2006; Blasco \& Soibbrio, 2012). As different media has its specific strengths and weaknesses, optimizing the effectiveness of media selection is an important decision-making process for business leaders, and good media often indicates that it will inspire greater awareness and affection while minimizing the impact of shortcomings, which can be measured by message persuasion and exposure frequency (Kwak, Lee, \& Kim, 2005).

Consumers' beliefs and involvement are important criteria for media selection. Wang and Sun (2010) conducted a research on people's beliefs and involvement toward internet advertisements, and they claimed that poor beliefs and engagements in advertising media were associated with a weak purchase intention. Bir, Suher,Şener, and Algür (2011) claim that people's perceptions of advertising are formed mainly due to their predetermined 
ideas of advertising and what they think of the function advertising serves; selecting media that is more trusted by the customers might thus influence the marketing results a great deal. Jarvis, Gainforth, and Latimer-Cheung (2014) stress the believability of both the message and the media. They assert that only when consumers are confident with the advertising messages will they act on it. Therefore, the success of media campaigns often depends on the right selection of both message and media (Spielmann \& Richard, 2013).

Exposure frequency is another important measure of advertisement media because higher exposure to advertisements often promotes higher consumptions of different commodities (Halford, Gillespie, Brown, Pontin, \& Dovey, 2004; Lee, Kim, Lee, Yoon, \& Chung, 2013). However, Nettelhorst and Brannon (2012) argue that higher exposure frequency is sometimes effective only with a certain group of people while it might be useless to other people. Therefore, it is important to recognize how exposure frequency can influence the target customers and what media can drive higher exposure frequency.

\subsection{Advertisement Messages for Student Recruitment}

In general, prospective students have to consider what is essential for them to study in a higher educational level, and then make a rational trade-off among the factors. Therefore, it is essential for schools to understand why students chose particular school if the aim is to develop sound marketing strategies that are fit to their prospective customers' needs (Cubillo, Sanchez, \& Cerviño, 2006).

Chapman (1979) argues that the two most important factors affecting students' school selection process are the quality of college and price -related considerations, and the price-related issues such as tuition, grants, scholarships, part-time working opportunities often become more important during economic difficulties. Quality factors as well as price factors are often interact with one another, and therefore, it is important to draw an integral picture of all these factors when developing marketing strategies. Szekeres (2010) provide school selection determinants very similar to Chapman, and he claims that students often select their destination schools based on the general quality reputation of the school. They might focus on the following attributes of a school: access to the school, surrounding of the campus, job prospects, school location, quality of faculty and their instruction, tuition and living costs.

Kallio (1995) examines the relative influence of factors affecting the school choice decisions of students, and he point out that the following factors are of great importance for enrollment decisions: the academic reputation of the institution, program quality and size, tuition costs and financial aids, school location and distance from residence, quality and access of faculty members, diversity of course and activitiesand opportunity for friendships. He further reminds us that students' personal characteristics significantly affect their school selection patterns.

\subsection{Strengths and Weaknesses of Distinct Media}

Advances in information technology have provided consumers with more choices in selecting methods for information collection. As consumers' attention is spread over more media than ever before, using only one medium for advertising can no longer guarantee that businesses will reach the targeted customer groups. For this reason, developing an adequate media mix that incorporates different kinds of media is more practical and popular (Chang, Wu, Tseng, Su, \& Ko, 2012; Sung \& Cho, 2012; Spielmann \& Richard, 2013). Optimizing the media mix requires a thorough understanding of the characteristics of different media. Thus, this section analyzes the strengths and weaknesses of distinct media.

Television advertisements often force consumers to use multiple sensory modes, making it easier for auditors to build emotional connections with advertising products (Dijkstra, Buijtels, \& Raaij, 2005; O'Hara, Bauman, \& Phongsavan, 2012). However, the information conveyed by television is abrupt and quick, making it difficult to facilitate consumers' ability to remember the information required for final purchase (Sung \& Cho, 2012).

Radio-based advertisements are relatively inexpensive to produce and broadcast compared to televised advertisements, and sometimes they have greater reach than television if the target group is low and if audiences are comprised primarily of middle-income population. However, without the visual effects, radio advertisements are less impressive than television advertisements (Durkin \& Wakefield, 2009).

Among the traditional mass media, newspapers and magazines are classified as print media. These sets of media allow customers to acquire the message they need at their own pace and emotion while enabling prospective consumers to retain the information for use at any time. Moreover, as the costs for print media advertisements are lower than for televised commercials, they are very popular among industries with lower marketing budgets (Esteban \& Hernández, 2012; Wei \& Pan, 1999; Kwak, Lee, \& Kim, 2005). However, print media is somewhat boring because print media advertisements cannot vividly convey visual and audio images; therefore, they are 
disadvantaged in influencing less involved or passive consumers (Dijkstra, Buijtels, \& Raaij, 2005).

Like magazine advertisements, direct-to-customer advertisements are beneficial for providing segmented and targeted consumer group messages in detail and tend to provoke more conative responses than all other media; thus, they are more credible and trusted among audiences (Feld, Frenzen, Krafft, Peters, \& Verhoef, 2013; Davis, 1996; O’Hara, Bauman, \& Phongsavan, 2012; Kiernan, Phillips, Fair, \& King, 2000). Some can argue that direct mail could be expensive in terms of the huge amount of mailing costs. These costs, in practice, can often be efficiently reduced by adopting a good plan for segmentation and targeting, timing, and sequencing (Feld, Frenzen, Krafft, Peters, \& Verhoef, 2013).

Internet advertisements seem to be the latest and the most popular medium among advertisers. The evolution of the World Wide Web has enabled new types of integrated publications that include features from different traditional media, such as television, radio, newspapers, and magazines (Rosales, 2012). The internet is different from traditional counterparts in that it is a many-to-many and a two-way communication model. In other words, it allows several users to communicate and interact with one another simultaneously (Subramaniam, Shaw, \& Gardner, 2000). The internet media are especially effective in providing consumers with a chance to make purchases immediately. Hence, the internet can provoke more conative responses than all the other traditional media (Dijkstra, Buijtels, \& Raaij, 2005). However, the security matters and technical issues often hinder industries from adopting the internet as the major advertisement media. Moreover, internet advertisements should not be used as the primary source of information for customers who do not have the intention or ability to access the internet, such as older adults (Berry, Spence, Plotnikoff, Bauman, McCargar, Wicher, Clark, \& Stolp, 2009).

\section{Methodology}

\subsection{Development}

This research aims to explore how students at different education levels use advertisement media to search for information they need for school selection. To actualize the aim, a self-developed questionnaire entitled "Research Questionnaire on Advertisement Media Engagement by Students at Different Educational Levels" was adopted as the main instrument.

The questionnaire was composed of four parts. The first part collected participants' demographic information. The second part contained 16 questions using a five-point Likert scale $(1=$ not persuasive at all, $5=$ very persuasive) examining which message contents were more persuasive for students. The third part contained 15 questions using a five-point Likert scale ( $1=$ never, $5=$ very often) examining students' exposure to different media. Finally, the fourth part contained 15 questions measuring the peak timing for different media; participants were asked to indicate the highest-use periods for each medium.

\subsection{Validity and Reliability}

The draft of the questionnaire was first screened by five scholars in educational administration to ensure the adequacy of the factors included in the questionnaire. The questionnaire was then pre-tested on 20 students, and minor revisions were made based on their feedbacks. Thereafter, Cronbach's $\alpha$ and factor analyses were adopted to ensure the content reliability and constructional validity. We first conducted a factor analysis on the second part of the questionnaire (examining message persuasion) using a Kaiser-Meyer-Olkin measure of sampling adequacy equal to .915 (very close to 1 , and much higher than .5) as well as Bartlett's test of sphericity equal to 9816.064 $(p=.000)$, indicating that the data set was adequate for factor analysis. The results identified three factors: reputation, environment, and economy, which accounted for $24.1 \%, 18.641 \%$, and $18.664 \%$ of the variance respectively. The three factors accounted for a total of $61.406 \%$ of the variability in all variables, as revealed in table 1 .

Table 1. Factor analysis loading of message persuasiveness items

\begin{tabular}{llccc}
\hline Number & \multicolumn{1}{c}{ Item } & Reputation & Environment & Economy \\
\hline Q1 & Rated the top in the university rankings & .774 & \\
Q2 & Alumni with outstanding achievements & .666 & \\
Q3 & Distinguished quality faculty & .756 & \\
Q4 & Richness and diversity of the curricula & .626 & .406 \\
\hline
\end{tabular}




\begin{tabular}{llll}
\hline Q5 & High quality assurance confirmations (ISO) & .586 & .609 \\
Q6 & Great students' achievements in off-campus exams and contests & & .764 \\
Q7 & Safe and comfortable facilities, buildings, and campus & .789 \\
Q8 & Richness and variety of student clubs and activities & .693 \\
Q9 & Location advantages and travel conveniences & .668 \\
Q10 & Complete and convenient living functions & .404 & .831 \\
Q11 & Reasonable tuition and school fees & .846 \\
Q12 & Lower living costs & & .619 \\
Q13 & Abundant scholarships and fellowships & & .693 \\
Q14 & Abundant part-time working opportunities & & .545 \\
Q15 & Competitiveness in graduate employability & .608 & \\
Q16 & Chances for advancing to higher academic levels & & \\
\hline
\end{tabular}

Thereafter, another factor analysis was conducted for the third part of the questionnaire (examining media exposure frequency), using Kaiser-Meyer-Olkin measure of sampling adequacy equal to .920 (very close to 1 , and much higher than .5) and Bartlett's test of sphericity equal to $6462.480(p=.000)$, indicating that the data set is adequate for factor analysis. The results identified three factors: mainstream media, alternative media, and internet media, which accounted for $17.479 \%, 19.894 \%$, and $19.711 \%$ respectively. The three factors accounted for a total of $57.084 \%$ of the variability in all variables, as shown in table 2 .

Table 2. Factor analysis loading of media items

\begin{tabular}{|c|c|c|c|c|}
\hline Number & Item & Mainstream Media & Alternative Media & Internet Media \\
\hline Q1 & Radio broadcast & .667 & & \\
\hline Q2 & Television & .751 & & \\
\hline Q3 & Newspaper & .678 & & \\
\hline Q4 & Movie or other motion pictures & .650 & & \\
\hline Q5 & Magazines & .509 & .470 & \\
\hline Q6 & Direct mail & & .676 & \\
\hline Q7 & Off-campus billboard, LED board & & .705 & \\
\hline Q8 & On-campus billboard, LED board & & .655 & \\
\hline Q9 & Wagon and station advertisement & & .584 & \\
\hline Q10 & Yellow page advertisement & & .651 & \\
\hline Q11 & Social media advertisement & & & .710 \\
\hline Q12 & Blog-based advertisement & & & .735 \\
\hline Q13 & Search engine banner ads & & & .760 \\
\hline Q14 & YouTube and game platform ads & & & .770 \\
\hline Q15 & School website advertisement & & .487 & .491 \\
\hline
\end{tabular}

To ensure that the instrument consistently measured the same variables, Cronbach's $\alpha$ was adopted for the reliability examination. The second part of the questionnaire had a Cronbach's $\alpha$ of .919 , much higher than the cutoff point of .7, indicating a very good reliability. Another Cronbach's $\alpha$ was conducted to test the third part of the questionnaire. The Cronbach's $\alpha$ equal to .896 indicated a good reliability of the question set.

\subsection{Target Groups and Sample Distribution}

This research explored the media usage pattern of students at different levels when making school-selection 
decisions, with a special concentration on how educational level might affect students' media usage patterns. The research groups targeted students from different levels (elementary school, junior high school, senior high school, and university). A total of 1200 questionnaires were administered to students: 300 to elementary students, 300 to junior high school students, 300 to senior high school students, and 300 to university students studying at a variety of locations in Taiwan. Ultimately, 293, 296, 289, and 294 questionnaires were returned, respectively. With a total number of 1175 , the response rate was $97.9 \%$. Of the 1175 returned questionnaires, 567 were from males and 605 from females; 179 were from metropolitan city centers, and 983 were from suburban and rural townships.

\section{Research Results}

\subsection{Message Persuasion}

Our first research question sought to understand message persuasiveness for students from different educational levels. Table 3 indicated that students stress safe and comfortable facilities, buildings, and campus most, followed by richness and variety of student clubs and activities and competitiveness in graduate employability. Messages related to alumni with outstanding achievements and abundant part-time working opportunities seemed less persuasive to students.

Table 3. Persuasiveness of advertisement messages

\begin{tabular}{lcc}
\hline \multicolumn{1}{c}{ Variables } & Mean & Std \\
\hline Excellent in the school evaluation or rankings & 3.52 & .93 \\
Alumni with outstanding achievements & 3.29 & .95 \\
Distinguished quality faculty & 3.66 & .96 \\
Richness and diversity of the curricula & 3.77 & .98 \\
High quality assurance confirmations (ISO) & 3.50 & .94 \\
Great students' achievements in off-campus exams and contests & 3.56 & .94 \\
Safe and comfortable facilities, buildings, and campus & 3.91 & .98 \\
Richness and a variety of student clubs and activities & 3.83 & 1.04 \\
Location advantages and travel conveniences & 3.77 & 1.05 \\
Complete and convenient living functions & 3.79 & 1.04 \\
Reasonable tuition and school fees & 3.73 & 1.05 \\
Lower living costs & 3.67 & 1.03 \\
Abundant scholarships and fellowships & 3.71 & 1.06 \\
Abundant part-time working opportunities & 3.38 & 1.13 \\
Competitiveness in graduate employability & 3.80 & 1.13 \\
Competitiveness in advancing to higher academic levels & 3.70 & 1.10 \\
\hline
\end{tabular}

\subsection{The Effects of Educational Level on Message Persuasion}

The last research question sought to understand how students' demographic backgrounds might affect their media usage pattern, and the most important variable in this research is students' educational level. We first examined whether students at different educational levels varied in opinions toward message persuasiveness. Table 4 indicates that elementary school students ranked it as less persuasive on almost every advertising message than students from all other levels. In contrast, university students gave a higher score on almost every message items. However, senior high school students gave higher scores on messages of complete and convenient living function and abundant scholarships and fellowships than their university counterparts. As students from different levels can focus on different messages, it is important for advertisers to recognize which messages are more persuasive to each group of students. 
Table 4. One-way ANOVA of educational level on message persuasion

\begin{tabular}{lccl}
\hline Variables & F & Sig. & Post-Hoc \\
\hline Excellent in the school evaluation or rankings & 8.42 & .000 & $(4),(3)>(2)>(1) ;$ \\
Alumni with outstanding achievements & .47 & .704 & n.s. \\
Distinguished quality faculty & 7.23 & .000 & $(3)>(1) ;(4)>(1),(2)$ \\
Richness and diversity of the curricula & 2.80 & .039 & n.s. \\
High quality standard authorizations (ISO) & 1.47 & .220 & n.s. \\
Great students' achievements in off-campus contests & 5.74 & .001 & $(4)>(3),(2)$ \\
Safe and comfortable facilities, buildings, and campus & 3.24 & .022 & n.s. \\
Richness and a variety of student clubs and activities & 13.98 & .000 & $(4)>(3),(2),(1)$ \\
Location advantages and travel conveniences & 4.78 & .003 & $(4)>(3)$ \\
Complete and convenient living functions & 6.51 & .000 & $(2)>(1) ;(3)>(4),(1)$ \\
Reasonable tuition and school fees & 8.33 & .000 & $(4),(3),(2)>(1)$ \\
Lower living costs & 4.20 & .006 & $(4)>(1)$ \\
Abundant scholarships and fellowships & 3.23 & .022 & $(3)>(4)$ \\
Abundant part-time working opportunities & 5.57 & .001 & $(3),(2)>(1)$ \\
Competitiveness in graduate employability & 10.10 & .000 & $(4),(3),(2)>(1)$ \\
Competitiveness in advancing to higher academic levels & 5.97 & .000 & $(4),(3),(2)>(1)$ \\
\hline
\end{tabular}

(4)=university, (3)=senior high school, (2)=junior high school, (1)=elementary school.

\subsection{Students' Media Exposure Frequency}

Our second research question examined the exposure frequency of students to advertisements carried by different media. The results showed that students are mostly exposed to television commercials, followed by internet search engine banner advertisements, YouTube and game platform advertisements, and on-campus billboard or LED board. In contrast, yellow page advertisements, blog-based advertisements, direct mail, and magazine advertisements are less frequently adopted by students when searching for school information (see table 5).

Table 5. Exposure frequency of media among students

\begin{tabular}{lll}
\hline \multicolumn{1}{c}{ Variables } & Mean & Std. \\
\hline Radio broadcast & 2.80 & 1.02 \\
Television & 3.63 & 1.02 \\
Newspaper & 2.98 & 1.01 \\
Movie or other motion pictures & 3.07 & 1.03 \\
Magazines & 2.78 & 1.00 \\
Direct mail & 2.77 & 1.04 \\
Off-campus billboard, LED ads board, or T-bar & 2.83 & 1.03 \\
On-campus billboard, LED board, or banners & 3.12 & 1.03 \\
Wagon advertisement and station advertisement & 2.93 & 0.97 \\
Yellow page advertisement & 2.25 & 0.97 \\
Social media advertisement & 3.04 & 1.22 \\
Blog-based advertisement & 2.71 & 1.12 \\
Internet search engine banner advertisement & 3.24 & 1.16 \\
YouTube and game platform click advertisement & 3.12 & 1.17 \\
School website advertisement & 2.91 & 1.05 \\
\hline
\end{tabular}




\subsection{The Effects of Educational Level on Exposure Frequency}

Finally, we examined whether students at different educational levels varied in media exposure frequency. As shown in table 6, students from higher educational levels tended to have higher exposure frequency to media than their counterparts from lower educational levels. Moreover, there were no significant differences among students from different levels in terms of direct mail and yellow page advertisements; one possible reason for these results is because students from higher educational levels often have to decide which school to go mostly by themselves, and they comparatively have more time, capability, and necessity to access more information than elementary and junior high school students. Moreover, since students from every educational level do not use direct mail and yellow page anymore, the variation among students from different educational levels on these two media are not significant.

Table 6. One-way ANOVA of educational level on message exposure frequency

\begin{tabular}{lccl}
\hline Variables & F & Sig. & Post-Hoc \\
\hline Radio broadcast & 3.090 & .026 & n.s. \\
Television advertisements & 6.737 & .000 & $(4),(3),(2)>(1)$ \\
Newspaper & 7.060 & .000 & $(4),(3)>(1)$ \\
Movie or other motion pictures & 4.020 & .007 & $(4)>(1)$ \\
Magazines & 9.451 & .000 & $(4)>(1) ;(3)>(2),(1)$ \\
Direct Mail & 1.315 & .268 & n.s. \\
Off-campus billboard or LED advertisements & 9.329 & .000 & $(4),(3),(2)>(1)$ \\
On-campus billboard or LED advertisements & 21.128 & .000 & $(4),(3),(2)>(1)$ \\
Wagon and station advertisements & 8.688 & .000 & $(4),(3),(2)>(1)$ \\
Yellow page advertisements & .156 & .926 & $n . s$. \\
Social media advertisements & 27.374 & .000 & $(4)>(3),(2),(1) ;(3),(2)>(1)$ \\
Blog-based advertisements & 42.195 & .000 & $(4)>(3),(2),(1) ;(3)>(2)$ \\
Search engine banner advertisements & 55.370 & .000 & $(4)>(3)>(2),(1)$ \\
YouTube and game platform advertisements & 27.422 & .000 & $(4)>(3),(2),(1) ;(3)>(1)$ \\
School website advertisements & 4.781 & .003 & $(4)>(3),(2),(1)$ \\
\hline
\end{tabular}

(4)=university, (3)=senior high school, (2)=junior high school, (1)=elementary school.

\subsection{Timing of Media Usage}

In the fourth part of the questionnaire, participants were asked to indicate the peak usage times for each advertising medium, but they were allowed to ignore a medium without marking on it if they did not use that medium often. Thereafter, the total number of the marks for each medium was calculated for different educational levels (as shown in Table 7). The results showed that students from all educational levels (elementary, junior high school, senior high school, and university) use media advertisements mostly between 18:00 and 20:00, followed by the period 20:00-22:00 and 16:00-18:00. However, students from different levels varied when looking at the fourth highest time period: elementary school students, junior high school students, and senior high school students rated the timing of 6:00-8:00 as the fourth highest, while university students marked 22:00-24:00 as the fourth highest. The possible reason for this might be that younger students (i.e., at the elementary school, junior high school, and senior high school levels) have to wake up early and get to school at about 7:30 in Taiwan; therefore, 6:00-8:00 is a good time for them to use media. Meanwhile, university students often stay up late, so 22:00-24:00 is a popular time for them to access advertising media.

Table 7. Exposure frequency in different periods

\begin{tabular}{lrrrrrrrrrrr}
\hline Time Period & \multicolumn{1}{r}{$0-6$} & \multicolumn{1}{c}{$6-8$} & $8-10$ & $10-12$ & $12-14$ & $14-16$ & $16-18$ & $18-20$ & $20-22$ & $22-24$ \\
\hline Elementary & 191 & $\mathbf{3 5 0}$ & 296 & 279 & 239 & 329 & $\mathbf{7 0 7}$ & $\mathbf{9 4 3}$ & $\mathbf{6 0 8}$ & 176 \\
Junior high & 190 & $\mathbf{4 6 0}$ & 173 & 177 & 186 & 263 & $\mathbf{8 4 1}$ & $\mathbf{1 2 1 3}$ & $\mathbf{9 7 7}$ & 334 \\
Senior high & 115 & $\mathbf{4 7 0}$ & 289 & 280 & 263 & 337 & $\mathbf{7 6 6}$ & $\mathbf{1 1 6 6}$ & $\mathbf{8 2 7}$ & 289 \\
University & 97 & 215 & 390 & 475 & 633 & 546 & $\mathbf{8 3 5}$ & $\mathbf{1 2 6 9}$ & $\mathbf{1 2 2 1}$ & $\mathbf{6 4 7}$ \\
\hline
\end{tabular}


We subsequently conducted an analysis of the peak time period for each medium and found that the peak time varied by medium. Table 8 shows that the best time for magazine advertisements, direct mail, yellow page advertisements, social media advertisements, blog-based advertisements, search engine banner advertisements, YouTube and game platform advertisements, and school website advertisements was 18:00-20:00, while the peak timing for radio broadcasts, newspaper advertisements, and on-campus billboard and LED board was 6:00-8:00. Finally, the top time period for movies or other motion picture advertisements was 20:00-22:00.

Table 8. Peak timing of each medium

\begin{tabular}{lcccccccccc}
\hline Time Period & 0 to 6 & 6 to 8 & 8 to 10 & 10 to 12 & 12 to 14 & 14 to 16 & 16 to 18 & 18 to 20 & 20 to 22 & 22 to 24 \\
\hline 1 Radio broadcasts & 48 & $\mathbf{1 9 8}$ & 40 & 32 & 42 & 34 & 163 & 193 & 174 & 80 \\
2 Television commercials & 43 & 79 & 48 & 65 & 92 & 77 & 285 & $\mathbf{6 4 3}$ & 464 & 185 \\
3 Newspaper advertisements & 39 & $\mathbf{1 8 9}$ & 135 & 74 & 64 & 51 & 157 & 185 & 135 & 29 \\
4 Movie advertisements & 28 & 45 & 45 & 68 & 52 & 88 & 170 & 313 & $\mathbf{3 2 0}$ & 105 \\
5 Magazines advertisements & 20 & 61 & 67 & 77 & 73 & 67 & 151 & $\mathbf{2 2 1}$ & 149 & 35 \\
6 Direct mail & 23 & 57 & 55 & 48 & 60 & 73 & 184 & $\mathbf{2 1 7}$ & 112 & 29 \\
7 Off-campus billboard and LED board & 28 & 75 & 78 & 79 & 103 & 117 & $\mathbf{2 0 8}$ & 198 & 109 & 34 \\
8 On-campus billboard and LED board & 49 & $\mathbf{3 0 2}$ & 228 & 208 & 213 & 188 & 267 & 144 & 80 & 30 \\
9 Wagon and station advertisements & 32 & 154 & 64 & 75 & 90 & 139 & $\mathbf{3 1 8}$ & 198 & 105 & 31 \\
10 Yellow page advertisements & 55 & 33 & 25 & 29 & 28 & 36 & 83 & $\mathbf{1 2 5}$ & 74 & 25 \\
11 Social media advertisements & 68 & 113 & 141 & 161 & 171 & 192 & 310 & $\mathbf{4 8 3}$ & 435 & 207 \\
12 Blog-based advertisements & 35 & 39 & 41 & 47 & 52 & 70 & 164 & $\mathbf{3 5 4}$ & 303 & 128 \\
13 Search engine banner ads & 50 & 52 & 62 & 84 & 105 & 128 & 258 & $\mathbf{5 0 8}$ & 453 & 209 \\
14 YouTube and game platform ads & 34 & 50 & 55 & 69 & 81 & 107 & 241 & $\mathbf{4 6 9}$ & 464 & 209 \\
15 School website advertisements & 41 & 48 & 64 & 95 & 95 & 108 & 190 & $\mathbf{3 4 0}$ & 256 & 110 \\
\hline
\end{tabular}

\section{Conclusions and Implications}

Studies of customer's reaction to media advertisements have become even more important today in the field of marketing because customers have become more cautious, demanding, and selective. Educational institutions are no exception. Recognizing what perspective students care most, and through what media the advertisement message can be expressed more effectively and efficiently to students, is crucial for student recruitment endeavors. This research thus sought to identify messages that are most persuasive for students, recognize media that enjoy the highest exposure frequency among students, and ascertain the peak timing when each medium is used. Moreover, this research also aimed to compare the media usage pattern variances among students from different educational levels.

Several managerial recommendations for schools at different levels can be developed from the research results. First, the results on the persuasiveness of student recruitment messages have shed some light on optimizing school promotion campaigns. Schools at all levels should highlight the messages about their safe and comfortable facilities, buildings and campus, and richness and variety of student clubs because these messages are most stressed by their perspective students. In contrast, although many schools currently put the acquirement of high quality assurance confirmations (such as ISO 9001 or 9002) as well as remarkable students' achievements in off-campus contests as the major elements in their advertising messages, their prospective customers actually overlook these messages, which in turn reduced the effectiveness of their advertising efforts. Thus, schools must seriously reconsider replacing these messages in the future.

Media exposure frequency is another key element in media strategies. As students indicated that they are most frequently exposed to television commercials, internet search engine banner advertisements, and game platform propaganda, schools should consider these media when developing their promotional strategies. In contrast, radio broadcasts, yellow page advertisements, direct mailings, and blog-based advertisements are not adequate for conveying messages about student recruitment. 
Peak timing is another crucial element in advertisement strategies, and the research results indicated that different media experience very different peak times. The peak time for radio broadcasts, newspaper advertisements, and on-campus billboard and LED board is 6:00 to 8:00 in the morning. Wagon and station advertisements and off-campus billboards showed the highest usage from 16:00 to 18:00. Television commercials, magazines advertisements, social media advertisements, blog-based advertisements, search engine banner advertisements, and game platform-based advertisements were most often used from 18:00 to 20:00. Finally, the peak time for movie commercials was 20:00 to 22:00. Schools should plan their media strategies in line with these peak times.

Students from different backgrounds vary widely in their media usage patterns, and schools have to develop their promotion strategies in line with students' media usage patterns to successfully increase enrollment. For example, schools can stress the complete and convenient living functions, abundant scholarships, and part-time working opportunities when attracting senior high school students while emphasizing location advantages and traveling conveniences and a wide variety of student clubs when university students are targeted for marketing.

\section{References}

Bir, A. A., Suher, K., Şener, G., \& Algür, A. (2011). Turkish university students' media usage and their attitudes toward advertising-in-general. Journal of Yaşar University, 24(6), 4098-4111.

Berry, T. R., Spence, J. C., Plotnikoff, R. C., Bauman, A., McCargar, L., Witcher, C., Clark, M., \& Stolp, S. (2009). A mixed methods evaluation of televised health promotion advertisements targeted at older adults. Evaluation and Program Planning, 32(3), 278-288. http://dx.doi.org/10.1016/j.evalprogplan.2009.05.001

Blasco, A., \& Sobbrio, F. (2012). Competition and commercial media bias. Telecommunications Policy, 36(5), 434-447. http://dx.doi.org/10.1016/j.telpol.2011.11.021

Chapman, R. G. (1979). Pricing policy and the college choice process. Research in Higher Education, 10(1), 37-57. http://dx.doi.org/10.1007/BF00977498

Chang, S., Wu, T., Tseng, H., Su, Y., \& Ko, C. (2012). Media mix decision support for schools based on analytic network process. International Journal of Industrial Engineering, 19(7), 297-304.

Chaudhuri, A., \& Buck, R. (1995). Media differences in rational and emotional responses to advertising. Journal of Broadcasting and Electronic Media, 39(1), 109-125. http://dx.doi.org/10.1080/08838159509364291

Collins, P. A., Abelson, J., Pyman, H., \& Lavis, J. N. (2006). Are we expecting too much from print media? An analysis of newspaper coverage of the 2002 Canadian healthcare reform debate. Social Science and Medicine, 63, 89-102. http://dx.doi.org/10.1016/j.socscimed.2005.12.012

Cubillo, J. M., Sanchez, J., \& Cerviño, J. (2006). International students' decision-making process. International Journal of Educational Management, 20(2), 101-115. http://dx.doi.org/10.1108/09513540610646091

Davis, J. F. (1996). The perceived value of direct mail advertising in small retail firms: Threat to local newspaper? Journal of Direct Marketing, $10(4), \quad$ 41-51. http://dx.doi.org/10.1002/(SICI)1522-7138(199623)10:4<41::AID-DIR4>3.0.CO;2-X

Dijkstra, M., Buijtels, H. E., \& Van Raaij, W. F. (2003). Separate and joint effects of medium type on consumer responses: A comparison of television, print, and the internet. Journal of Business Research, 58(3), 377-386. http://dx.doi.org/10.1016/S0148-2963(03)00105-X

Durkin, S., \& Wakefield, M. (2009). Comparative responses to radio and television anti-smoking advertisements to encourage smoking cessation. Health Promotion International, 25(1), 5-13. http://dx.doi.org/10.1093/heapro/dap044

Esteban, L., \& Hernández, J. M. (2012). Specialized advertising media and product market competition. Journal of Economics, 106, 45-74. http://dx.doi.org/10.1007/s00712-011-0243-7

Feld, S., Frenzen, H., Krafft, M., Peters, K., \& Verhoef, P. C. (2013). The effects of mailing design characteristics on direct mail campaign performance. International Journal of Research in Marketing, 30, 143-159. http://dx.doi.org/10.1016/j.ijresmar.2012.07.003

Halford, J. C. G., Gillespie, J., Brown, V., Pontin, E. E., \& Dovey, T. M. (2004). Effect of television advertisements for foods on food consumption in children. Appetite, 42(2), 221-225. http://dx.doi.org/10.1016/j.appet.2003.11.006

Jarvis, J. W., Gainforth, H. L., \& Latimer-Cheung, A. E. (2014). Investigating the effect of message framing on parents' engagement with advertisements promoting child physical activity. International Review on Public 
and Nonprofit Marketing. http://dx.doi.org/10.1007/s12208-013-0110-z

Kallio, R. E. (1995). Factors influencing the college choice decisions of graduate students. Research in Higher Education, 36(1), 109-124. http://dx.doi.org/10.1007/BF02207769

Kiernan, M., Phillips, K., Fair, J. M., \& King, A. C. (2000). Using direct mail to recruit Hispanic adults into a dietary intervention: An experimental study. Annals of Behavioral Medicine, 22(1), 89-93. http://dx.doi.org/10.1007/BF02895172

Kopperschmidt, K., \& Stute, W. (2009). Purchase timing models in marketing: a review. AStA Advetisement Status Anal, 93, 123-149. http://dx.doi.org/10.1007/s10182-008-0096-8

Kwak, N. K., Lee, C. W., \& Kim, J. H. (2005). An MCDM model for media selection in the dual consumer/industrial market. European Journal of Operational Research, 166, $255-265$. http://dx.doi.org/10.1016/j.ejor.2004.02.016

Lee, B., Kim, H., Lee, S., Yoon, J., \& Chung, S. (2014). Effects of exposure to television advertising for energy-dense/nutrient-poor food on children's food intake and obesity in South Korea. Appetite, 81, 305-311. http://dx.doi.org/10.1016/j.appet.2014.06.103

Nettelhorst, S. C., \& Brannon, L. A. (2012). The effect of advertisement choice on attention. Computers in Human Behavior, 28(2), 683-687. http://dx.doi.org/10.1016/j.chb.2011.11.015

Hara, B. J., Bauman, A. E., \& Phongsavan, P. (2012). Using mass-media communications to increase population usage of Australia's get healthy information and coaching service. BMC Public Health, 12(762), 1-11.

Rizvi, S. A. A., \& Khan, M. N. (2010). The uniqueness of educational marketing. Journal of Economics and Engineering, 4, 39-43.

Rosales, R. G. (2012). Citizen participation and the uses of mobile technology in radio broadcasting. Telematics and Informatics, 30(3), 252-257. http://dx.doi.org/10.1016/j.tele.2012.04.006

Slade, C. (2002). Reasons to buy: The logic of advertisements. Argumentation, 16, $157-178$. http://dx.doi.org/10.1023/A:1015512825071

Spielmann, N., \& Richard, M. (2013). How captive is your audience? Defining overall advertising involvement. Journal of Business Research, 66, 499-505. http://dx.doi.org/10.1016/j.jbusres.2011.12.002

Subramaniam, C., Shaw, M. J., \& Gardner, D. M. (2000). Product marketing and channel management in electronic commerce. Information Systems $\quad$ Frontiers, $1(4), \quad 363-378$. http://dx.doi.org/10.1023/A:1010061924822

Sung, J., \& Cho, K. (2012). The influence of media type on attitude toward mobile advertisements over time. Cyberpsychology, Behavior, and Social Networking, $15(1), \quad 31-36$. http://dx.doi.org/10.1089/cyber.2011.0061

Szekeres, J. (2010). Sustaining student numbers in the competitive marketplace. Journal of Higher Education Policy and Management, 32(5), 429-439. http://dx.doi.org/10.1080/1360080X.2010.511116

Wang, Y., \& Sun, S. (2010). Assessing beliefs, attitudes, and behavioral responses toward online advertising in three countries. International Business Review, $333-344$. http://dx.doi.org/10.1016/j.ibusrev.2010.01.004

Wei, R., \& Pan, Z. (1999). Mass media and consumerist values in the People's Republic of China. International Journal of Public Opinion Research, 11(1), 75-96. http://dx.doi.org/10.1093/ijpor/11.1.75

\section{Copyrights}

Copyright for this article is retained by the author(s), with first publication rights granted to the journal.

This is an open-access article distributed under the terms and conditions of the Creative Commons Attribution license (http://creativecommons.org/licenses/by/3.0/). 